\title{
Bioresorbable vascular scaffolds in left main coronary artery disease
}

Bert Everaert $^{1}, \mathrm{MD}, \mathrm{PhD}$; Piera Capranzano², MD; Corrado Tamburino², MD, PhD; Ashok Seth ${ }^{3}$, MD, FRCP, DSc; Robert-Jan M. van Geuns ${ }^{1 *}, \mathrm{MD}, \mathrm{PhD}$

1. Thoraxcenter, Erasmus Medical Centre, Rotterdam, The Netherlands; 2. Cardiovascular Department, Ferrarotto Hospital, University of Catania, Catania, Italy; 3. Fortis Escorts Heart Institute, New Delhi, India

The complete references and the accompanying supplementary data are published online at: http://www:pcronline.com/eurointervention/V_issue/30

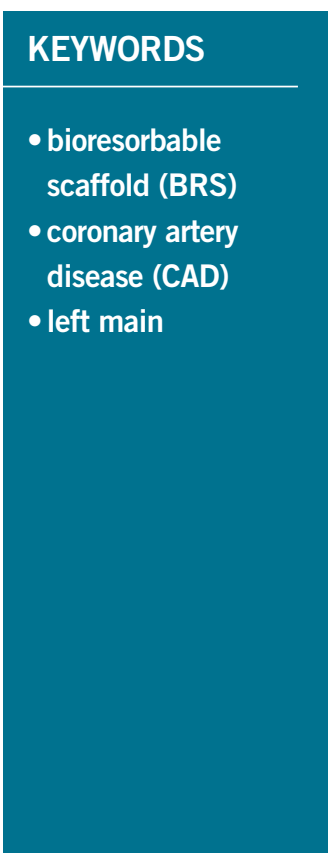

\section{Abstract}

Currently, the use of bioresorbable vascular scaffolds (BRS) for the treatment of left main (LM) coronary artery disease has to be considered investigational. However, some early evidence from case reports supports the feasibility of BRS implantation in selected cases and shows good angiographic and clinical results with current-generation BRS devices. However, before the routine use of BRS for LM disease can be advocated, more data on long-term safety and efficacy and larger scaffold designs are essential.

*Corresponding author: Department of Cardiology, Thoraxcenter, Room Ba-585, Erasmus University Medical Centre,

s-Gravendijkwal 230,3015 GE Rotterdam, The Netherlands. E-mail: rvangeuns@erasmusmc.nl 


\section{Introduction}

Percutaneous coronary intervention (PCI) has become a reliable revascularisation option for the treatment of ischaemic coronary artery disease $(\mathrm{CAD})^{1}$. Several recent trials have suggested that PCI with metallic drug-eluting stents (DES) is feasible and safe and has equivalent long-term outcomes compared to coronary artery bypass grafting $(\mathrm{CABG})$ for the treatment of LM stenosis in patients with a low to intermediate SYNTAX score $(<33)^{2,3}$.

However, these permanent implants continue to remain a foreign body, even after vascular healing following the PCI, and this leads to rates of target vessel failure of more than $2 \%$ per year ${ }^{4}$. To eliminate this and other potential limitations of a permanent metallic implant, bioresorbable coronary stents or "scaffolds" (BRS) have been developed.

Currently, the use of BRS for the treatment of left main (LM) coronary artery stenosis has not been properly studied and is therefore considered investigational. However, limited evidence from case reports supports the feasibility of BRS implantation in these patients and shows good angiographic and clinical results in the short term. With the limited expansion capacity of currently available BRS devices there is a justified concern for BRS malapposition and subsequent BRS failure particularly in this patient population. Therefore, for routine use in LM disease, larger scaffold designs and long-term safety and efficacy data are essential.

\section{Indications for LM revascularisation}

CABG is still considered as the "gold standard" treatment for most patients with LM disease. However, several studies have indicated equally good clinical outcomes comparing CABG to $\mathrm{PCI}$ in patients with low to intermediate SYNTAX scores $(\leq 32)^{2-4}$.

When considering PCI for the treatment of LM CAD, besides the SYNTAX score, other lesion characteristics are predictive of a favourable clinical outcome, such as lesion location (ostial or shaft), isolated LM disease, LM in combination with single-vessel disease, plaque distribution pattern favouring a single-stent crossover technique and limited calcium burden ${ }^{5}$. Importantly, when using DES, patients have to be able to comply with dual antiplatelet therapy (DAPT) for several months.

In conclusion, with the advent of first and second-generation DES, PCI has become a valuable treatment strategy in selected patients with LM disease.

\section{Technical considerations for BRS implantation in LM disease}

Several technical considerations, pertaining to the current generation of BRS, preclude its broad use in LM PCI (Table 1).

First and most important is the limited overexpansion capability of the current generation of BRS, impairing adequate stent apposition. As with other stent platforms ${ }^{6}$, BRS malapposition and/or incomplete lesion coverage are expected to increase the risk of BRS failure, i.e., by a higher incidence of acute and chronic scaffold thrombosis and in-scaffold restenosis. As the expansion limit of the largest commercially available Absorb BVS (Absorb $3.5 \mathrm{~mm}$;

Table 1. Current limitations of BRS in the setting of LM disease.

Limited BRS lengths

Restricted BRS expansion limit: $\leq 4.0 \mathrm{~mm}$ with Absorb BVS ( $\leq 4.5 \mathrm{~mm}$ with DESolve)

Lower radial strength compared to metallic stent platforms

Limited side branch fenestration capabilities

Optimal lesion preparation with extensive balloon dilatation required

Abbott Vascular, Santa Clara, CA, USA) is restricted to $0.5 \mathrm{~mm}$, vessels with a diameter greater than $4.0 \mathrm{~mm}$ (quantitatively measured by IVUS or OCT, and $3.8 \mathrm{~mm}$ for QCA) should not be treated because of the high risk of malapposition. As LM diameters are often considerably larger than $4.0 \mathrm{~mm}$, only a small proportion of patients are suitable for BRS implantation ${ }^{7}$. Other bioresorbable devices, such as the DESolve ${ }^{\mathrm{TM}}$ myolimus-eluting bioresorbable coronary scaffold system (Elixir Medical Corporation, Sunnyvale, CA, USA) or the magnesium-based drug-eluting absorbable metal scaffold platform DREAMS (Biotronik AG, Bülach, Switzerland), are currently under investigation but could overcome some of these issues. The DESolve BRS has been designed with unique expansion capabilities, such as the ability to expand within a wide safety margin without strut fracture (the $3.0 \mathrm{~mm}$ scaffold can be expanded to $4.5 \mathrm{~mm})^{8}$, which could make this a potentially useful BRS platform for LM interventions in the future, when larger scaffold diameters of the DESolve become available. Also, the DREAMS platform could become an alternative to the polymeric scaffolds for LM CAD, because the mechanical properties of the magnesium alloy are comparable to those of permanent metallic stent platforms, resulting in an increased deliverability and a reduced incidence of strut fractures 9 . However, initial data on the bare metal version of this latter device showed significant late lumen loss and a higher rate of target vessel revascularisation. Data from the BIOSOLVE-II study investigating the new second-generation DREAMS platform are still not available. This stent is not commercially available and larger stent diameters would be needed to treat LM stenosis.

Secondly, to minimise the risk of BRS malapposition in the LM, correct scaffold sizing based on a reliable assessment of LM dimensions should always include invasive imaging modalities such as IVUS or OCT. These techniques have proven to be superior to angiography in providing accurate estimations of LM diameter, lesion length and the involvement of the LM bifurcation and its distal side branches. Of note, OCT is particularly suited to optimising BRS implantation ${ }^{10,11}$ (i.e., to determine optimal scaffold size and length, identify optimal proximal and distal landing zones and guide postdilatation of the scaffold to perfect strut apposition).

Thirdly, the radial strength of all PLLA-based scaffold designs is outperformed by cobalt-chromium and especially platinum-chromium stent platforms. LM PCI for ostial disease frequently suffers from acute stent recoil due to the fibroelastic properties of the aortic wall and the increased presence of calcium. To attain sufficient radial strength (on average one bar), the strut thickness of BRS has to be larger, which affects the scaffold's crossing profile. However, 
with adequate predilatation and lesion preparation, this generally does not compromise the scaffold deliverability particularly in LM disease. While there is a concern that aggressive balloon dilatations within a highly calcified LM could potentially result in LM dissection with serious consequences, calcified lesions at other non-LM sites have regularly been treated successfully with BRS after adequate lesion preparation by high-pressure non-compliant balloon dilatation, cutting balloon or rotational atherectomy.

Fourthly, Absorb BVS have to be expanded gradually by increasing the inflation pressure by two atmospheres (atm) every five seconds, terminating with a long inflation of approximately 30 seconds. Thus, for a $3.5 \mathrm{~mm}$ Absorb BVS to be expanded to its expansion limit of $4.0 \mathrm{~mm}$ at $16 \mathrm{~atm}$, in total approximately $65 \mathrm{~s}$ of occlusion of the LM are needed. In the setting of LV dysfunction and/or if the right coronary artery is diseased, these prolonged inflation times could result in ischaemic complications of severe hypotension or life-threatening arrhythmias.

Another technical concern, although minor, may be the challenging ostial positioning with no radiopaque scaffolds.

\section{LM BIFURCATION LESIONS}

Bifurcation lesions in appropriately selected patients are potentially good candidates for BRS treatment. However, as most $(40 \%$ to $96 \%$ in different series) LM lesions involve the LM bifurcation and $70 \%$ to $80 \%$ of LM disease patients present with multivessel disease $^{12}$, although theoretically sound, the LM bifurcation is less attractive for BRS treatment. Unprotected distal LM bifurcation PCI is always a challenging procedure and has worse long-term clinical outcomes than the more favourable results obtained with ostial- or shaft-LM lesions, especially when a two-stent approach is used ${ }^{13}$. In the SYNTAX study, $63 \%$ of LM lesions involved the left main bifurcation and required treatment. Of these, $>90 \%$ had plaque extension into the left anterior descending (LAD) coronary artery and about $3 / 4$ into the circumflex (LCx) territory.

At this moment the data on BRS bifurcation techniques are still limited compared to metallic DES bifurcation techniques, although even for metal DES there are no good systematic data supporting one bifurcation technique over another for LM bifurcation stenting $^{14}$. For use of BRS in a coronary bifurcation, the European Bifurcation Club (EBC) proposed the strategy of provisional side branch crossover scaffolding with a proximal optimisation technique (POT) for proper apposition, side branch dilatation in case of TIMI flow $<2$ or symptoms of angina at low pressures (max. $8 \mathrm{~atm}$ ), and a second stent (DES or scaffold) as bail-out with final POT (Table 2) ${ }^{15}$. However, bench testing using bifurcation phantoms has been performed to assess the safety and efficacy of side branch dilatation through the BRS and main branch post-dilatation techniques. Strut fractures were not observed at low inflation pressures, but high inflation pressures or larger side branch balloons frequently caused BRS strut fractures and/or lumen compromise ${ }^{16}$. When a two BRS strategy has to be used, a provisional T-stenting or TAP technique is recommended in the majority of cases. However, at least in a bifurcation phantom model, other contemporary
Table 2. Current EBC recommendations for BRS use in bifurcations.

Use provisional approach with side branch (SB) crossover scaffolding

Proximal optimisation technique (POT) with non-compliant (NC) balloon (max $0.5 \mathrm{~mm}$ above nominal scaffold diameter) is recommended

Side branch dilatation only when compromised

Second stent (DES or scaffold) in SB only for bail-out

Final POT after SB dilatation/scaffolding

bifurcation techniques, such as the culotte, double-crush or minicrush, performed well using the Absorb BVS ${ }^{17}$. These techniques are generally not advocated for use with BRS in small vessel bifurcations, as they would result in $\geq 2$ or 3 layers of scaffold struts leading to a serious luminal reduction and a high chance of delayed healing. However, in particular in the setting of an LM bifurcation with a main branch lumen of 3.5-4.0 $\mathrm{mm}$, such a luminal reduction over a short coronary segment may be tolerated (Figure 1, Moving image 1 - Moving image 16). As the expansion capabilities
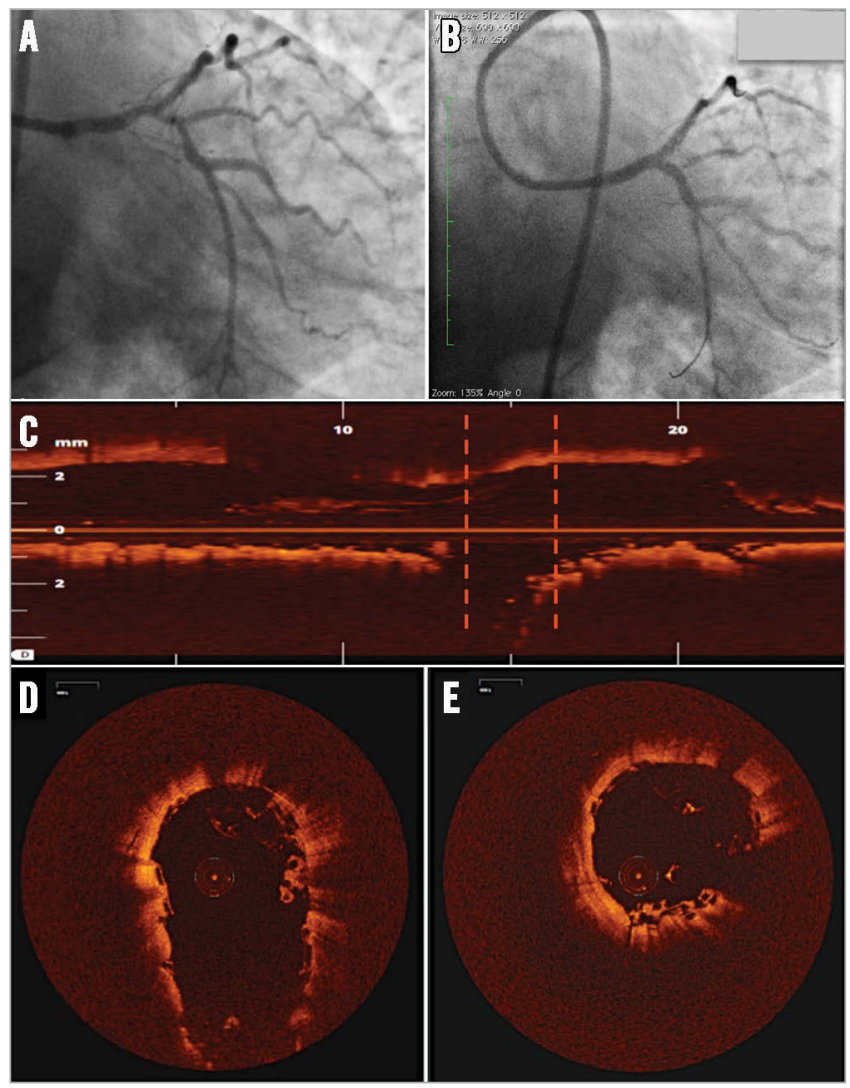

Figure 1. LM bifucation lesion treated with mini-crush technique and final kissing balloon post-dilatation. Distal LM lesion before (A) and after treatment with two Absorb BVS (LCX and LM-LAD), mini-crush and final kissing balloon post-dilatation (B). OCT of LM-LAD showing good stent apposition (C). Red dotted lines: OCT images of LM bifurcation (D) and LM carina (E). Three layers of Absorb BVS struts are visible at the carina. 
of the Absorb BVS are limited, simultaneous kissing balloon postdilatation is usually not recommended while sequential POT, side branch post-dilatation and final POT were proposed at the last EBC meeting. If simultaneous kissing dilatation is indicated, only low pressures (e.g., $5 \mathrm{~atm}$ ) and preferably with the side branch balloon protruding just outside the side branch, "snuggling" against the main branch balloon, are advised ${ }^{18}$. For POT, non-compliant balloons with a diameter no greater than $0.5 \mathrm{~mm}$ above nominal scaffold diameter should be used.

Also, intracoronary imaging with OCT should always be considered to determine optimal stent size and landing zones and is highly recommended to ensure adequate stent expansion and apposition in all LM bifurcation segments after the procedure.

\section{PATIENT CONSIDERATIONS IN LM DISEASE}

Patients presenting with LM disease tend to be older than the average PCI patient population ${ }^{2}$, leading to a higher bleeding risk and less preference for long-term DAPT. However, as a shorter DAPT duration for second-generation DES was recently shown to be safe $^{19}$, DAPT for $\geq 12$ months is still advocated for BRS because of the strut thickness and concerns about stent thrombosis ${ }^{20}$, making this technology less appropriate for patients with an increased risk of bleeding complications.

\section{Case reports on BRS use in LM disease}

Several authors have already reported on the successful use of Absorb BVS in LM disease. However, information on long-term
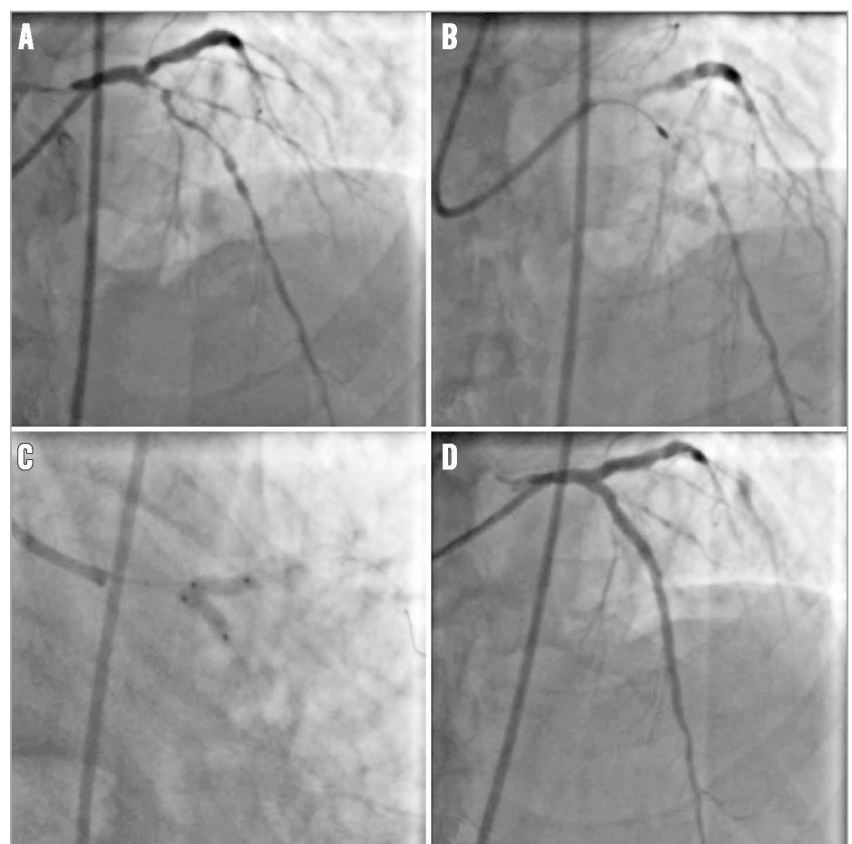

Figure 2. LM bifurcation stenosis treated with V-stenting. LM bifurcation stenosis (Medina 0,1,1) and diffuse calcification of the proximal and mid LAD (A). Rotational atherectomy of the LAD (B). $V$-stenting with a $3.5 \times 18 \mathrm{~mm}$ Absorb BVS in both LAD and LCX $(C)$. Final result after implantation of four Absorb BVS (three in the LAD, one in the $L C x)(D)$ follow-up is generally lacking. Fernandez et al described the case of a 56-year-old male patient with a history of CABG, who presented with an NSTEMI due to a severe lesion in the distal LM. The LAD was protected by a LIMA graft and was ostially occluded. The circumflex territory was, however, not protected. After predilatation, a $3.5 \times 18 \mathrm{~mm}$ Absorb BVS was expanded to $3.94 \mathrm{~mm}$ at $14 \mathrm{~atm}$ with good final angiographic result and no events at 30-day follow-up ${ }^{21}$. Two successful PCI cases, using a bifurcation crossover technique with stenting from LM towards the LAD and subsequent fenestration of the scaffold struts towards the circumflex artery, were published ${ }^{22,23}$. Cortese et al described nine patients with unprotected LM disease involving the bifurcation and a low SYNTAX score. A single-scaffold strategy was performed in all patients. Invasive imaging with IVUS showed four cases of scaffold underexpansion and one case of acute recoil. One patient developed recurrent angina 12 months after the index PCI due to late scaffold recoil and underwent $\mathrm{CABG}^{24}$. Furthermore, V-stenting with two Absorb BVS scaffolds for an LM bifurcation lesion has been described ${ }^{25}$, but after five months the patient presented with in-scaffold restenosis treated by PCI, as reported by Miyazaki et $\mathrm{al}^{26}$. Here, we report a new successful case of the V-stenting approach for treating a Medina 0,1,1 LM bifurcation stenosis (Figure 2). Finally, in the GHOST-EU trial, 17 of the 1,189 Absorb BVS-treated patients (1.2\%) received a scaffold for LM disease. Although one of these patients presented with a scaffold thrombosis at day 84 , unfortunately no further description of the implantation technique or of the individual patient outcomes was reported for the remaining 16 patients $^{20}$.

\section{Conclusions}

Taking everything into consideration, the use of BRS for the treatment of LM disease is presently generally not recommended and is considered to be investigational with current BRS platforms. However, in highly selected cases, the current BRS devices could still be applied with favourable results, especially in young patients with non-calcific LM lesions of $\leq 4.0 \mathrm{~mm}$ diameter with ostial or body disease or distal LM disease involving the LAD alone where a single crossover scaffold strategy can be applied. Before the use of BRS for LM disease can be advocated, more data on long-term safety and efficacy and larger scaffold designs are urgently needed.

\section{Conflict of interest statement}

C. Tamburino and R-J. van Geuns have received speaker's honoraria from Abbott Vascular. R-J. van Geuns has received research grants (institutional) from Abbott Vascular. The other authors have no conflicts of interest to declare.

\section{References}

The references can be found in the online version of the paper.

\section{Online data supplement}

Moving image 1-Moving image 16. LM bifucation lesion treated with mini-crush technique and final kissing balloon post-dilatation. 


\section{Online data supplement}

\section{References}

1. Deb S, Wijeysundera HC, Ko DT, Tsubota H, Hill S, Fremes SE. Coronary artery bypass graft surgery vs percutaneous interventions in coronary revascularization: a systematic review. JAMA. 2013;310:2086-95.

2. Windecker S, Kolh P, Alfonso F, Collet JP, Cremer J, Falk V, Filippatos G, Hamm C, Head SJ, Jüni P, Kappetein AP, Kastrati A, Knuuti J, Landmesser U, Laufer G, Neumann FJ, Richter DJ, Schauerte P, Sousa Uva M, Stefanini GG, Taggart DP, Torracca L, Valgimigli M, Wijns W, Witkowski A. 2014 ESC/EACTS guidelines on myocardial revascularization. EuroIntervention. 2015;10:1024-94.

3. Morice MC, Serruys PW, Kappetein AP, Feldman TE, Stahle E, Colombo A, Mack MJ, Holmes DR, Choi JW, Ruzyllo W, Religa G, Huang J, Roy K, Dawkins KD, Mohr F. Five-year outcomes in patients with left main disease treated with either percutaneous coronary intervention or coronary artery bypass grafting in the synergy between percutaneous coronary intervention with taxus and cardiac surgery trial. Circulation. 2014;129:2388-94.

4. Park SJ, Kim YH, Park DW, Yun SC, Ahn JM, Song HG, Lee JY, Kim WJ, Kang SJ, Lee SW, Lee CW, Park SW, Chung CH, Lee JW, Lim DS, Rha SW, Lee SG, Gwon HC, Kim HS, Chae IH, Jang Y, Jeong MH, Tahk SJ, Seung KB. Randomized trial of stents versus bypass surgery for left main coronary artery disease. $N$ Engl J Med. 2011;364:1718-27.

5. Park SJ, Park DW. Left main stenting: is it a different animal? EuroIntervention. 2010;6 Suppl J:J112-7.

6. Roy P, Waksman R. Intravascular ultrasound guidance in drug-eluting stent deployment. Minerva Cardioangiol. 2008;56: 67-77.

7. Shand JA, Sharma D, Hanratty C, McClelland A, Menown IB, Spence MS, Richardson G, Herity NA, Walsh SJ. A prospective intravascular ultrasound investigation of the necessity for and efficacy of postdilation beyond nominal diameter of 3 current generation DES platforms for the percutaneous treatment of the left main coronary artery. Catheter Cardiovasc Interv. 2014;84:351-8.

8. Verheye S, Ormiston JA, Stewart J, Webster M, Sanidas E, Costa R, Costa JR Jr, Chamie D, Abizaid AS, Pinto I, Morrison L, Toyloy S, Bhat V, Yan J, Abizaid A. A next-generation bioresorbable coronary scaffold system: from bench to first clinical evaluation: 6- and 12-month clinical and multimodality imaging results. JACC Cardiovasc Interv. 2014;7:89-99.

9. Haude M, Erbel R, Erne P, Verheye S, Degen H, Böse D, Vermeersch P, Wijnbergen I, Weissman N, Prati F, Waksman R, Koolen J. Safety and performance of the drug-eluting absorbable metal scaffold (DREAMS) in patients with de-novo coronary lesions: 12 month results of the prospective, multicentre, first-inman BIOSOLVE-I trial. Lancet. 2013;381:836-44.

10. Allahwala UK, Cockburn JA, Shaw E, Figtree GA, Hansen PS, Bhindi R. Clinical utility of optical coherence tomography (OCT) in the optimisation of Absorb bioresorbable vascular scaffold deployment during percutaneous coronary intervention. EuroIntervention. 2015;10:1154-9.

11. Brown AJ, McCormick LM, Braganza DM, Bennett MR, Hoole SP, West NE. Expansion and malapposition characteristics after bioresorbable vascular scaffold implantation. Catheter Cardiovasc Interv. 2014;84:37-45.

12. Taggart DP, Kaul S, Boden WE, Ferguson TB Jr, Guyton RA, Mack MJ, Sergeant PT, Shemin RJ, Smith PK, Yusuf S. Revascularization for unprotected left main stem coronary artery stenosis stenting or surgery. J Am Coll Cardiol. 2008;51:885-92.

13. Teirstein PS, Price MJ. Left main percutaneous coronary intervention. J Am Coll Cardiol. 2012;60:1605-13.

14. Chen SL, Zhang Y, Xu B, Ye F, Zhang J, Tian N, Liu Z, Qian X, Ding S, Li F, Zhang A, Liu Y, Lin S. Five-year clinical follow-up of unprotected left main bifurcation lesion stenting: onestent versus two-stent techniques versus double-kissing crush technique. EuroIntervention. 2012;8:803-14.

15. Lassen JF, Holm NR, Stankovic G, Lefèvre T, Chieffo A, Hildick-Smith D, Pan M, Darremont O, Albiero R, Ferenc M, Louvard Y. Percutaneous coronary intervention for coronary bifurcation disease: consensus from the first 10 years of the European Bifurcation Club meetings. EuroIntervention. 2014;10:545-60. 16. Ormiston JA, Webber B, Ubod B, Webster MW, White J. Absorb everolimus-eluting bioresorbable scaffolds in coronary bifurcations: a bench study of deployment, side branch dilatation and post-dilatation strategies. EuroIntervention. 2015;10:1169-77.

17. Džavík V, Colombo A. The absorb bioresorbable vascular scaffold in coronary bifurcations: insights from bench testing. JACC Cardiovasc Interv. 2014;7:81-8.

18. Seth A, Sengottuvelu G, Ravisekar V. Salvage of side branch by provisional "TAP technique" using Absorb ${ }^{\text {TM }}$ bioresorbable vascular scaffolds for bifurcation lesions: first case reports with technical considerations. Catheter Cardiovasc Interv. 2014;84:55-61.

19. Colombo A, Chieffo A, Frasheri A, Garbo R, MasottiCentol M, Salvatella N, Oteo Dominguez JF, Steffanon L, Tarantini G, Presbitero P, Menozzi A, Pucci E, Mauri J, Cesana BM, Giustino G, Sardella G. Second generation drug-eluting stent implantation followed by six- versus twelve-month dual antiplatelet therapy: the SECURITY randomized clinical trial. J Am Coll Cardiol. 2014;64:2086-97.

20. Capodanno D, Gori T, Nef H, Latib A, Mehilli J, Lesiak M, Caramanno G, Naber C, Di Mario C, Colombo A, Capranzano P, Wiebe J, Araszkiewicz A, Geraci S, Pyxaras S, Mattesini A, Naganuma T, Münzel T, Tamburino C. Percutaneous coronary intervention with everolimus-eluting bioresorbable vascular scaffolds in routine clinical practice: early and midterm outcomes from the European multicentre GHOST-EU registry. EuroIntervention. 2015;10:1144-53 
21. Fernández D, Brugaletta S, Martín-Yuste V, Regueiro A, de Mingo A, Santos A, Masotti M, Sabaté M. First experience of a bioresorbable vascular scaffold implantation in left main stenosis. Int J Cardiol. 2013;168:1566-8.

22. Grundeken MJ, Kraak RP, de Bruin DM, Wykrzykowska JJ. Three-dimensional optical coherence tomography evaluation of a left main bifurcation lesion treated with $\mathrm{ABSORB}^{\circledR}$ bioresorbable vascular scaffold including fenestration and dilatation of the side branch. Int J Cardiol. 2013;168:e107-8.

23. Miyazaki T, Panoulas VF, Sato K, Naganuma T, Latib A, Colombo A. Bioresorbable vascular scaffolds for left main lesions; a novel strategy to overcome limitations. Int J Cardiol. 2014;175: e11-3.
24. Cortese B, Orrego PS, Sebik R, Sesana M, Pisano F, Zavalloni D, Steffenino G, Seregni R; RAI registry investigators. Biovascular scaffolding of distal left main trunk: experience and follow up from the multicenter prospective RAI registry (Registro Italiano Absorb). Int J Cardiol. 2014;177:497-9.

25. Sato K, Latib A, Panoulas VF, Naganuma T, Miyazaki T, Colombo A. A case of true left main bifurcation treated with bioresorbable everolimus-eluting stent v-stenting. JACC Cardiovasc Interv. 2014;7:e103-4.

26. Miyazaki T, Panoulas VF, Sato K, Kawamoto H, Naganuma T, Latib A, Colombo A. In-scaffold restenosis in a previous left main bifurcation lesion treated with bioresorbable scaffold v-stenting. JACC Cardiovasc Interv. 2015;8:e7-e10. 